\title{
Research Article \\ Estimation of Saturation Flow Rates at Signalized Intersections
}

\author{
Chang-qiao Shao and Xiao-ming Liu \\ Key Lab of Transportation Engineering, Beijing University of Technology, Beijing 100124, China \\ Correspondence should be addressed to Chang-qiao Shao, shaocq@bjut.edu.cn
}

Received 26 August 2012; Revised 11 October 2012; Accepted 27 October 2012

Academic Editor: Wuhong Wang

Copyright (C) 2012 C.-q. Shao and X.-m. Liu. This is an open access article distributed under the Creative Commons Attribution License, which permits unrestricted use, distribution, and reproduction in any medium, provided the original work is properly cited.

\begin{abstract}
The saturation flow rate is a fundamental parameter to measure the intersection capacity and time the traffic signals. However, it is revealed that traditional methods which are mainly developed using the average value of observed queue discharge headways to estimate the saturation headway might lead to underestimate saturation flow rate. The goal of this paper is to study the stochastic nature of queue discharge headways and to develop a more accurate estimate method for saturation headway and saturation flow rate. Based on the surveyed data, the characteristics of queue discharge headways and the estimation method of saturated flow rate are studied. It is found that the average value of queue discharge headways is greater than the median value and that the skewness of the headways is positive. Normal distribution tests were conducted before and after a log transformation of the headways. The goodness-of-fit test showed that for some surveyed sites, the queue discharge headways can be fitted by the normal distribution and for other surveyed sites, the headways can be fitted by lognormal distribution. According to the queue discharge headway characteristics, the median value of queue discharge headways is suggested to estimate the saturation headway and a new method of estimation saturation flow rates is developed.
\end{abstract}

\section{Introduction}

The saturation flow rate is a fundamental parameter to measure the intersection capacity and time the traffic signals. Traditional saturation flow rate estimation methods were mostly developed based on the assumption that the queue discharge headway is a fairly constant and that the average headway estimated from the first 4-to-10 or 4-to-12 vehicles is representative of the saturation headway $(h)$ meaning every vehicle in a stable moving platoon consumes $h$ seconds $[1,2]$. However, variability in queue discharge headways is addressed in more recent studies [2-14] and it is found that traditional methods which simply use the average of discharge headway to estimate the saturation headway might lead to underestimate 
saturation flow rate. Errors in saturation flow rates used to estimate vehicle delays carry over onto delay predictions and level of service (LOS) predictions. Therefore, it is necessary to study and to improve accuracy of the estimation of saturation flow rate. Due to the fact that driver behavior is the main determinate of saturation flow rate, a good understanding of the discharge headway of individual vehicles is essential in estimation of saturation headway and saturation flow rate.

However, the distribution characteristic of headways and its effect on the estimation of saturation flow rate have not been examined in literatures. The goal of this paper is to investigate the stochastic nature of queue discharge headways, which may provide better information, and, so, to develop a new saturation flow rate estimation method. To fulfill the objective, a literature review, data collection and data analysis, and model development were conducted.

\section{Literature Review}

Due to the importance of the queue discharge headways and the saturation flow rates in intersection capacity estimation and traffic control, researches have made great efforts to study the characteristics of discharge headways and saturation flow rates. $\mathrm{Li}$ and Prevedouros [2] applied three methodologies to analyze the saturation headway based on the field data. It was revealed that when long queues are present, the typical field measurement of saturation flow rate based on the first 12 vehicles is an overestimate of saturation flow rate for through vehicles and an underestimate of saturation flow rate for protected left-turning vehicles. Lu and Pernía [3] analyzed the differences of driving behavior among different driver age groups based on collected data at signalized intersections. And the variation in capacities with an increasing percentage of older drivers in the traffic stream was modeled. It was found that the presence of older drivers significantly reduced intersection capacity at all study sites because of their higher lost times and lower saturation flow rates. Hung et al. [4] performed one study on the discharge headways at 26 sites of signalized intersections in Hong Kong. It is concluded that discharge headway at different queue position follows the type I extreme value distribution. Mei and Bullen [5] analyzed the individual headways distribution for drivers in a car-following state and it was indicated that the lognormal distribution yielded a good fit for headways in busy traffic. Lin and Thomas [7] examined the queue discharge characteristics at three intersections on Long Island, New York. It is found that queue discharge rates often kept rising even after the 15th vehicle has entered the intersection. Jin et al. [8] also found that the distributions of the departure headways at each position in a queue approximately follow a certain log-normal distribution. Joseph and Chang [10] illustrated the field measurements of saturation flow headways and startup lost times and found that they varies significantly ranging from 1.63 to $1.91 \mathrm{~s}$. Long [11] indicated that traditional estimates of saturation flow rates have been challenged by field observations, and that large variations in saturation flow measurements have cast doubt on the presumption that the base saturation flow rate is either stable or a constant value. Rahman et al. [12] developed a new procedure for determining the saturation flow rates at signalized intersections and they concluded that the procedure as discussed in the HCM [1] would overestimate saturation flow rates for some approaches and underestimate them for the other approaches based on the field data. Shao et al. [13] reported some findings on the saturation flow rates at signalized intersections in China. It is shown that the average headway is about $2.03 \mathrm{~s}$ and the standard error is from $0.40 \mathrm{~s}$ to $0.90 \mathrm{~s}$. Sharma et al. [14] studied queue 
discharge characteristics at signalized intersections under heterogeneous traffic conditions and the effect of a countdown timer on the headway distribution. The results indicated that the accepted headway distribution is followed when there is no timer.

From the efforts of these researches, it can be concluded that the queue discharge headway is not constant due to various factors and that the effect of headway variations on the estimation of saturation flow rate should be considered.

\section{Queue Discharge Headway and Saturation Flow Rate}

Discharge headways at signalized intersections are defined as the time intervals between two successive vehicles passing a stop line or any predetermined reference line at the intersections. It can be expressed as the function of the driver response during queue discharge [15], spacing between vehicle in queue and queue discharge speed:

$$
h_{s}=t_{r}+\frac{L_{h j}}{v_{s}}
$$

where $h_{s}$ is the discharge headway(s); $t_{r}$ is the driver response time (s); $L_{h j}$ is queue space per vehicle (include vehicle length, $\mathrm{m}) ; v_{s}$ is the queued vehicle speed $(\mathrm{m} / \mathrm{s})$. From (3.1), it is easy to understand that the queue discharge headway $h_{s}$ is a random variable due to the difference of driver behavior (response time $t_{r}$ and variation in the length of queue space $L_{h j}$ $[2,15])$. In order to estimate the saturation headway, the average queue discharge headway is calculated as follows:

$$
\bar{h}_{s}=\frac{1}{n} \sum_{i=1}^{n} h_{s i}
$$

where, $\bar{h}_{s}$ is the average queue discharge headway(s) which can be taken as the estimation of saturation headway $h ; h_{s i}$ is the headway of vehicle $i$ in the queue, $i=1,2, \ldots, n$ ( $n$ is the sample size). And, consequently, the traditional saturation flow rate is determined by the queue discharge headway:

$$
S=\frac{3600}{\bar{h}_{s}}
$$

where, $S$ is the saturation flow rate (veh/h). According to the knowledge of statistics [16], when the distribution of queue discharge headways is symmetrical, the average headway calculated by (3.2) is unbiased estimation of $h$ and (3.3) can be a good estimation of the saturation flow rate. However, when the headway distribution is unsymmetrical, $\bar{h}_{s}$ is not a good estimation and (3.3) will overestimate or underestimate saturation flow rate. Therefore, it is necessary to learn about the stochastic nature of queue discharge headway and to analyze the effect of variation of headways on the estimation of saturation flow rate. 


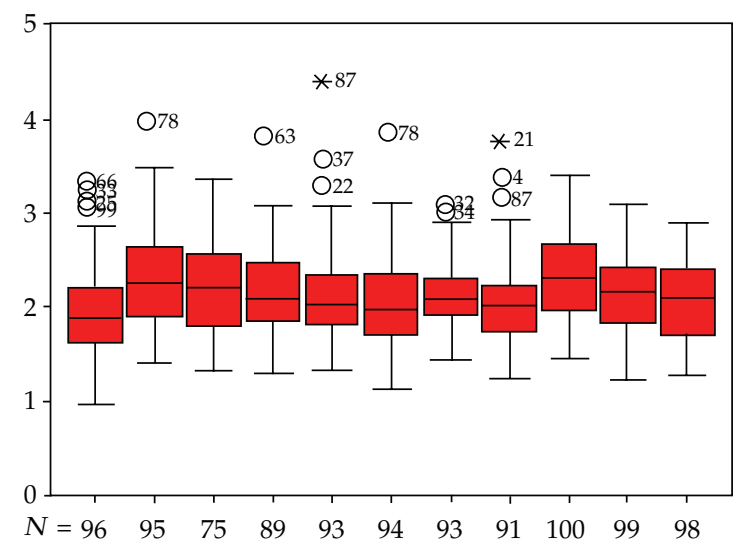

Figure 1: Boxplot of queue discharge headways.

\section{Methodology}

\subsection{Data Collection}

Discharge headway data were collected at 11 signalized intersections in Beijing. Surveys were conducted at the morning and evening peak periods (7:00 to 9:00 and 17:00 to 18:00) at weekdays by video cameras and the data were manually collected form the videotapes. Through the videotaping, the time for each vehicle rear bumper passing the stop line was recorded and the time headway was calculated.

In order to eliminate the effect of start-up and acceleration on the saturation flow rate, the first 5 headways in each signal cycle were removed from the data. Also, data which were apparently anomalous because the drivers are in distracted attention that causes the headway exceeded the normal ranges are eliminated. In addition, the signal cycle in which vehicles were seriously disturbed by pedestrians or bicycles is not included. A total of 1023 vehicle discharge headways were recorded.

\subsection{Data Analysis}

In order to investigate the queue discharge headway statistical characteristics, the surveyed headways at 11 sites of signalized intersections are analyzed (Table 1 presented the results). It is easily found that there are some differences in the queue discharge headways for different surveyed sites (Figure 1). However, there are still some interesting characteristics which should be noted. The average value of queue discharge headways is greater than the median value (the difference range from $0.0 \mathrm{~s}$ to $0.30 \mathrm{~s}$ ) which is consistent with the existing findings $[6,12,13]$. Also, it is found that the skewness of headways is positive. These characteristics indicate that the distribution of queue discharge headway is likely unsymmetrical and the normal distribution function is not appropriate to fit the headway data.

The fact that average value of queue discharge headway $\bar{h}_{s}$ is greater than the median value shows that more than $50 \%$ drivers will keep smaller headway than $\bar{h}_{s}$. Therefore, traditional saturation flow rate estimation method would underestimate the flow rates. 
Table 1: Statistical results for the queue discharge headways.

\begin{tabular}{lcccccc}
\hline $\begin{array}{l}\text { Code of } \\
\text { surveyed site }\end{array}$ & Sample size & Average & Median & Stand error & Skewness & Kurtosis \\
\hline 1 & 96 & 1.95 & 1.88 & 0.52 & 0.66 & 0.88 \\
2 & 95 & 2.36 & 2.28 & 0.55 & 0.61 & 1.22 \\
3 & 75 & 2.30 & 2.23 & 0.49 & 0.43 & -0.10 \\
4 & 89 & 2.22 & 2.14 & 0.37 & 0.88 & 1.09 \\
5 & 93 & 2.19 & 2.03 & 0.43 & 0.97 & 1.21 \\
6 & 94 & 2.08 & 1.98 & 0.47 & 0.43 & -0.34 \\
7 & 93 & 2.21 & 2.09 & 0.44 & 0.35 & -0.39 \\
8 & 91 & 2.04 & 2.00 & 0.43 & 0.81 & 1.11 \\
9 & 100 & 2.31 & 2.30 & 0.45 & 0.02 & -0.75 \\
10 & 99 & 2.18 & 2.16 & 0.46 & 0.07 & -0.73 \\
11 & 98 & 2.11 & 2.07 & 0.42 & 0.02 & -0.20 \\
\hline
\end{tabular}

\section{Discharge Headway Distribution}

According to the statistical analysis result of the surveyed queue discharge headway data, it is revealed that the sample average value is greater than median value and that queue discharge headway distribution is likely unsymmetrical. Recent research $[5,8]$ showed that the queue discharge headway could be fitted by lognormal distribution. So, in this paper, the lognormal distribution is chosen to fit the queue discharge headway data (as comparison, the normal tests for time headway data are also conducted). The lognormal distribution density function is

$$
f_{H}(h)=\frac{1}{\sqrt{2 \pi} \sigma h} \exp \left(-\frac{(\ln h-u)^{2}}{2 \sigma^{2}}\right), \quad h \geq 0 .
$$

The means, median, and variance of lognormal distribution are the following:

$$
\begin{gathered}
E(H)=\exp \left(\mu+0.5 \sigma^{2}\right), \\
\operatorname{Med}(H)=\exp (u), \\
\operatorname{Var}(H)=\exp \left(2 \mu+\sigma^{2}\right)\left(e^{\sigma^{2}}-1\right) .
\end{gathered}
$$

It is known that when the random variable $h_{s}$ density function is lognormal, then $\ln \left(h_{s}\right)$ will follow the normal distribution. Applying this quality of lognormal distribution, the hypothesis that discharge headway $h_{s}$ is lognormal distributed can be tested using normal test method (in this study, the Shapiro-Wilk method is used [17]). Table 2 listed the hypothesis test results. From Table 2, it is concluded that among the 11 surveyed sites, there are 7 signalized intersections at which queue discharge headways do not pass the normal distribution hypothesis test (with significant level $P(W \leq w) \leq 0.05$ ) while they pass the lognormal distribution hypothesis test (with significant level $P\left(W^{*} \leq w^{*}\right)>0.05$ ). On the contrary, there are 3 signalized intersections at which queue discharge headways pass the normal distribution hypothesis test $(P(W \leq w)>0.05)$ but they do not pass the lognormal 
Table 2: Result of headway distribution test.

\begin{tabular}{lccccccccccc}
\hline Code of surveyed site & 1 & 2 & 3 & 4 & 5 & 6 & 7 & 8 & 9 & 10 & 11 \\
\hline$w$ & 0.952 & 0.953 & 0.968 & 0.952 & 0.941 & 0.955 & 0.969 & 0.947 & 0.968 & 0.965 & 0.974 \\
$P(W \leq w)$ & 0.005 & 0.007 & 0.100 & 0.006 & 0.0006 & 0.012 & 0.069 & 0.003 & 0.116 & 0.064 & 0.239 \\
$w^{*}$ & 0.981 & 0.972 & 0.976 & 0.982 & 0.979 & 0.971 & 0.978 & 0.976 & 0.911 & 0.955 & 0.960 \\
$P\left(W^{*} \leq w^{*}\right)$ & 0.601 & 0.209 & 0.448 & 0.655 & 0.499 & 0.177 & 0.147 & 0.342 & 0.025 & 0.007 & 0.021 \\
\hline
\end{tabular}

$w$ and $w^{*}$ are Shapiro-Wilk statistics, $w^{*}$ is computed after log transformation.

distribution hypothesis test $\left(P\left(W^{*} \leq w^{*}\right)<0.05\right)$. There is only one site (code number is 3 ) which significant level of headway distribution being normal is 0.10 and significant level of being lognormal is 0.448 .

Therefore, among the surveyed 11 signalized intersections, there are 8 signalized intersections at which headway distribution is lognormal while the other 3 signalized intersections at which headway distribution is normal.

\section{New Estimation of Saturation Flow Rate}

\subsection{Estimation of Saturation Flow Rate Based on the Median Value of Queue Discharge Headways}

According to the analysis results of surveyed queue discharge headway data, the fact that for some signalized intersections, the queue discharge headways can be fitted by lognormal distribution means that the simple average of headway is not a good estimation and (3.3) will underestimate the saturation flow rate. Hence, it is reasonable to use the median value [16] to calculate the saturation flow rate and a new estimation is obtained:

$$
S_{1}=3600 \times \frac{1}{h_{\text {med }}}
$$

where $S_{1}$ is a new estimation of saturation flow rate (veh/h); $h_{\text {med }}$ is sample median value of headways or estimation of median headways. For the lognormal distribution (5.1), the likelihood estimations for parameters $\mu$ and $\sigma^{2}$ are noted as $\widehat{\mu}_{\mathrm{ML}}$ and $\widehat{\sigma}_{\mathrm{ML}}^{2}$, respectively. According to the statistical knowledge [16], $\widehat{\mu}_{\mathrm{ML}}$ and $\widehat{\sigma}_{\mathrm{ML}}^{2}$ can be expressed as

$$
\begin{gathered}
\widehat{\mu}_{\mathrm{ML}}=\frac{1}{n} \sum_{i=1}^{n} \ln h_{s i} \\
\widehat{\sigma}_{\mathrm{ML}}^{2}=\frac{1}{n} \sum_{i=1}^{n}\left[\ln h_{s i}-\frac{1}{n} \sum_{i=1}^{n} \ln h_{s i}\right]^{2}
\end{gathered}
$$


Let $\widehat{\mu}_{M}$ and $\widehat{\sigma}_{M}^{2}$ denote the moment estimations for parameters $\mu$ and $\sigma^{2}$. It is easily derived that

$$
\begin{gathered}
\widehat{\mu}_{M}=\ln \left(\frac{\bar{h}_{s}}{\sqrt{1+\sigma_{s}^{2} / \bar{h}_{s}^{2}}}\right), \\
\widehat{\sigma}_{M}^{2}=\ln \left(1+\frac{\sigma_{s}^{2}}{\bar{h}_{s}^{2}}\right) .
\end{gathered}
$$

From (5.3), (6.2), and (6.4), other two new estimations of saturation headway are obtained:

$$
\begin{gathered}
\widehat{\operatorname{Med}}\left(h_{s}\right)_{1}=\exp \left(\widehat{u}_{\mathrm{ML}}\right)=\exp \left(\frac{1}{n} \sum_{i=1}^{n} \ln h_{s i}\right), \\
\widehat{\operatorname{Med}}\left(h_{s}\right)_{2}=\exp \left(\widehat{u}_{M}\right)=\frac{\bar{h}_{s}}{\sqrt{1+{\sigma_{s}^{2} / \bar{h}_{s}^{2}}^{2}}} .
\end{gathered}
$$

Consequently, two new estimations of saturation flow rate are also suggested:

$$
\begin{gathered}
S_{2}=3600 \times \exp \left(-\frac{1}{n} \sum_{i=1}^{n} \ln h_{s i}\right), \\
S_{3}=\frac{3600}{\bar{h}_{s}} \times\left(1+\frac{\sigma_{s}^{2}}{\bar{h}_{s}^{2}}\right)^{0.5},
\end{gathered}
$$

where $S_{2}$ and $S_{3}$ are two new estimations of saturation flow rate $(\mathrm{veh} / \mathrm{h}) ; \sigma_{s}^{2}=[(1 / n-$ 1) $\left.\sum_{i=1}^{n}\left(h_{s i}-\bar{h}_{s}\right)^{2}\right]$ is the variance of sample headways.

Equation (6.7) is developed based on the likelihood estimation of median value and it is consistent with (6.1). Equation (6.8) includes information from both the average value of queue discharge headway $\bar{h}_{s}$ and variance $\sigma_{s}^{2}$. (Hence, the estimation takes into account the effect of queue discharge headway spread on the estimation.) It can be taken as the modification of (3.3).

\subsection{Comparison of Saturation Flow Rate Estimations}

Table 3 listed the saturation flow rates based on different estimation methods by using the surveyed data at 11 signalized intersections. For the first 8 signalized intersections (their queue discharge headways can be taken as being from lognormal distribution), the saturation flow rates are computed, respectively, using these methods developed in this paper. It can be found that the computed saturation flow rates based on median of queue discharge headways (6.1), (6.7), and (6.8) are very close to each other and higher than the values estimated by the traditional method (3.3) for each surveyed sites. For the other 3 signalized intersections 
Table 3: Comparison of computed saturations using different methods.

\begin{tabular}{lccccccc}
\hline \multirow{2}{*}{$\begin{array}{l}\text { Code of } \\
\text { surveyed site }\end{array}$} & $\begin{array}{c}\text { Headway } \\
\text { means (s) }\end{array}$ & $\begin{array}{c}\text { Seadway median (s) } \\
\text { median }\end{array}$ & $\begin{array}{c}\text { Saturation flow rates (veh/h) } \\
\text { Equation }\end{array}$ & $\begin{array}{c}\text { Equation } \\
\text { Equation }\end{array}$ & $\begin{array}{c}\text { Equation } \\
\text { Equation }\end{array}$ \\
\hline 1 & 1.95 & 1.88 & 1.88 & 1846 & 1914 & 1914 & 1911 \\
2 & 2.36 & 2.28 & 2.25 & 1525 & 1578 & 1600 & 1656 \\
3 & 2.30 & 2.23 & 2.18 & 1565 & 1614 & 1651 & 1600 \\
4 & 2.22 & 2.14 & 2.11 & 1621 & 1682 & 1706 & 1644 \\
5 & 2.19 & 2.03 & 2.06 & 1643 & 1773 & 1747 & 1675 \\
6 & 2.08 & 1.98 & 1.99 & 1730 & 1818 & 1809 & 1774 \\
7 & 2.21 & 2.09 & 2.12 & 1558 & 1723 & 1698 & 1660 \\
8 & 2.04 & 2.00 & 2.00 & 1764 & 1800 & 1800 & 1803 \\
9 & 2.31 & 2.30 & 2.27 & 1558 & 1565 & - & - \\
10 & 2.18 & 2.16 & 2.05 & 1651 & 1666 & - & - \\
11 & 2.11 & 2.07 & 2.06 & 1706 & 1739 & - & - \\
\hline
\end{tabular}

(their queue discharge headways can be taken as being from normal distribution), the saturation flow rates estimated by the method (6.1), developed in this paper, is near the value obtained by using the traditional method. Hence, these findings validated that when the headway distribution is unsymmetrical (e.g., lognormal distribution is unsymmetrical), the traditional method will underestimate the saturation flow rates. Otherwise, when the distribution is symmetrical (normal distribution is symmetrical), the saturation flow rate estimation method developed in this paper is consistent with the traditional method.

\section{Conclusions}

This paper reported results of the queue discharge headway distribution at 11 surveyed signalized intersections and the following conclusions can be made

(1) The average value of queue discharge headways is greater than the median value, and the skew of headways is positive.

(2) The goodness-of-fit test showed that for some surveyed sites, the headways follow the normal distribution and that for other surveyed sites, the queue discharge headways are lognormal distributed.

(3) The traditional estimation of saturation headway does not accurately reflect the true value of $h$ and would overestimate it. As a result, the traditional estimation of saturation flow rate would underestimate saturation flow rate.

(4) The new estimations of saturation flow rate developed in this study are more reasonable and they are suggested to be used in traffic control and measurement of intersection capacity.

In addition, it is found that for different signalized intersections, the queue discharge headway distribution can be not identical. Does it relate to the conditions or traffic circumstance? This is a new problem and needs to be verified. 


\section{Acknowledgments}

This work was supported by the National Key Basic Research Program of China under Grant no. 2012CB723303. The authors would like to thank the anonymous reviewers whose comments helped to significantly improve the overall quality of this paper.

\section{References}

[1] Transportation Research Board, Highway Capacity Manual 2000, National Research Council, Washington, DC, USA, 2000.

[2] H. Li and P. D. Prevedouros, "Detailed observations of saturation headways and start-up lost times," Transportation Research Record, no. 1802, pp. 44-53, 2002.

[3] J. J. Lu and J. C. Pernía, "The difference of driving behavior among different driver age groups at signalized intersections," IATSS Research, vol. 24, no. 2, pp. 75-84, 2000.

[4] W. T. Hung, F. Tian, and H. Y. Tong, "Discharge headway at signalized intersections in Hong Kong," Journal of Advanced Transportation, vol. 37, no. 1, pp. 105-117, 2003.

[5] M. Mei and A. G. R. Bullen, "Lognormal distribution for high traffic flows," Transportation Research Record, no. 1398, pp. 125-128, 1993.

[6] W. Wang, W. Zhang, H. Guo, H. Bubb, and K. Ikeuchi, "A safety-based behavioural approaching model with various driving characteristics," Transportation Research Part C, vol. 19, no. 6, pp. 12021214, 2011.

[7] F. B. Lin and D. R. Thomas, "Headway compression during queue discharge at signalized intersections," Transportation Research Record, no. 1920, pp. 81-85, 2005.

[8] X. Jin, Y. Zhang, F. Wang et al., "Departure headways at signalized intersections: a log-normal distribution model approach," Transportation Research Part C, vol. 17, no. 3, pp. 318-327, 2009.

[9] R. Akçelik, "An investigation of the performance of roundabout with metering signals," Paper for Presentation at the National Roundabout Conference, Transportation Research Board, Kansas City, Kan, USA, 2008.

[10] J. Joseph and G. L. Chang, "Saturation flow rates and maximum critical lane volumes for planning applications in Maryland," Journal of Transportation Engineering, vol. 131, no. 12, pp. 946-952, 2005.

[11] G. Long, "Driver behavior model of saturation flow," Transportation Research Record, no. 2027, pp. 65-72, 2007.

[12] M. Rahman, S. A. Nur-ud-deen, and T. Hassan, "Comparison of saturation flow rate at signalized intersections in Yokohama and Dhaka," Proceedings of the Eastern Asia Society for Transportation Studies, vol. 5, pp. 959-966, 2005.

[13] C. Q. Shao, J. Rong, and X. M. Liu, "Study on the saturation flow rate and its influence factors at signalized intersections in China," Procedia-Social and Behavioral Sciences, pp. 504-514, 2011.

[14] A. Sharma, L. Vanajakshi, and N. Rao, "Effect of phase countdown timers on queue discharge characteristics under heterogeneous traffic conditions," Transportation Research Record, no. 2130, pp. 93-100, 2009.

[15] R. Akçelik and M. Besley, "Queue discharge flow and speed models for signalized intersections," in Proceedings of the 15th International Symposium on Transportation and Traffic Theory, pp. 99-118, Pergamon, Elsevier Science, Oxford, UK, 2002.

[16] F. J. Wall, Statistical Data Analysis HandBook, Mcgraw-Hill, 1986.

[17] J. A. Rice, Mathematical Statistics and Data Analysis, Brooks/Cole, 2007. 


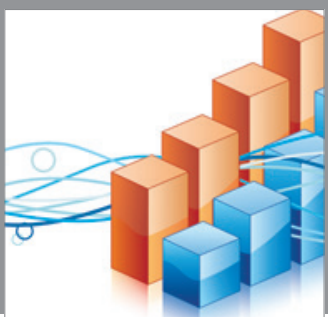

Advances in

Operations Research

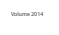

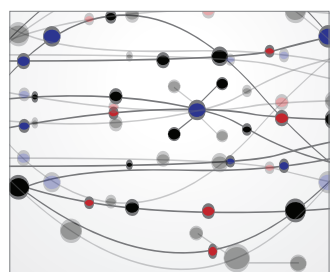

\section{The Scientific} World Journal
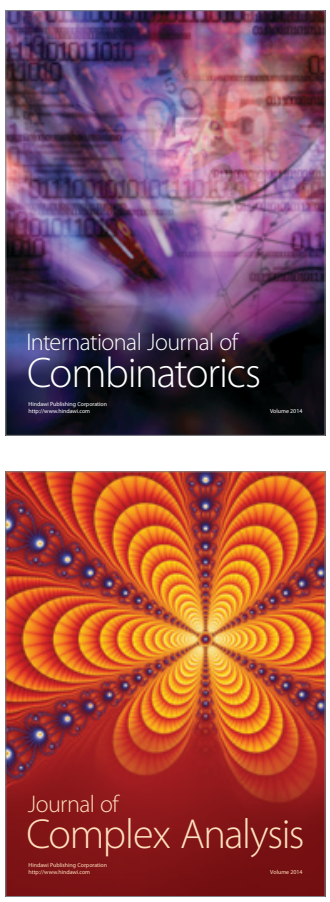

International Journal of

Mathematics and

Mathematical

Sciences
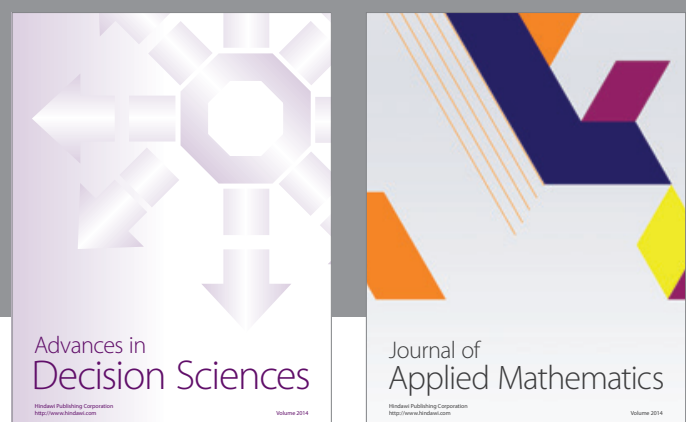

Journal of

Applied Mathematics
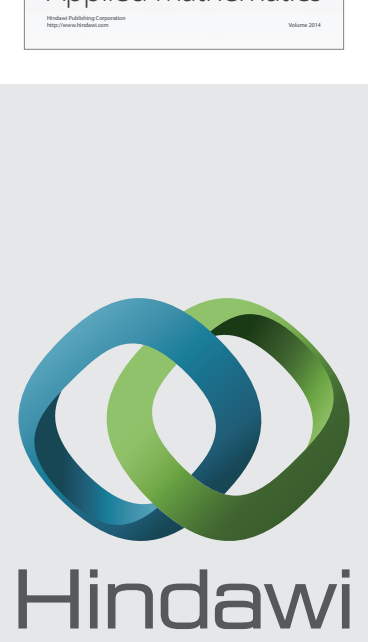

Submit your manuscripts at http://www.hindawi.com
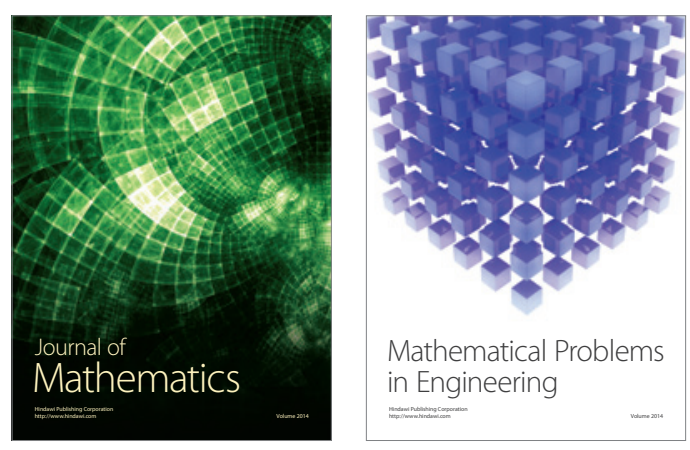

Mathematical Problems in Engineering
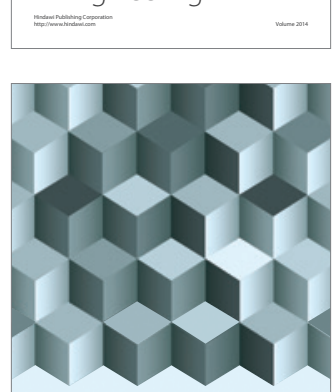

Journal of

Function Spaces
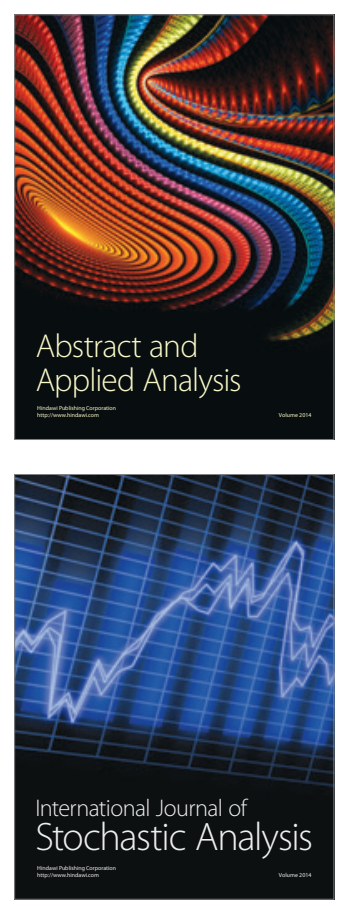

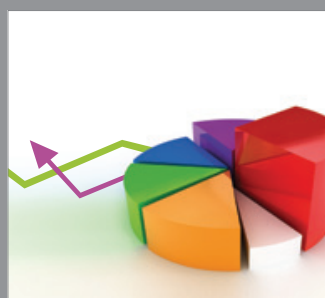

ournal of

Probability and Statistics

Promensencen
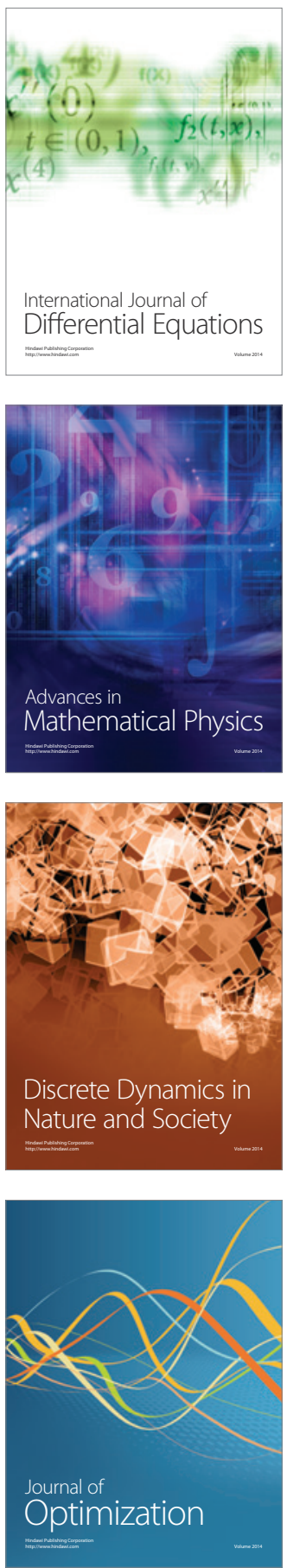